\title{
O conhecimento etnográfico dos Tremembé da Barra do Mundaú, Ceará
}

\author{
The ethnographic knowledge of the Tremembé from Barra do Mundaú, Ceará
}

\section{Connaissance du Tremembé ethnographiques Barra do Mundaú, Ceará}

\section{El conocimiento etnográfico de los Tremembé de la Barra do Mundaú, Ceará}

\author{
André Luís Aires Pinto ${ }^{1}$ \\ Maria Jardenes de Matos $^{1}$ \\ Maria do Socorro Moura Rufino ${ }^{1}$
}

Recebido em 31/05/2017; revisado e aprovado em 27/06/2017; aceito em 05/07/2017

DOI: http://dx.doi.org/10.20435/inter.v19i1.1623

\begin{abstract}
Resumo: A pesquisa empenhou-se em compreender o conhecimento tradicional dos Tremembé da Barra do Mundaú acerca das frutas nativas de seu território e em oferecer uma contribuição para a etnobotânica dos indígenas do Nordeste. Elegeu-se a metodologia etnográfica, com abordagem qualitativa. Os povos indígenas, à proporção que defendem a diversidade cultural, preservam os recursos naturais e os conhecimentos a eles associados.
\end{abstract}

Palavras-chaves: frutas; etnobotânica; conhecimento tradicional.

\begin{abstract}
The research was committed to understanding the traditional knowledge of the Tremembé ethnic group from Barra do Mundaú concerning the native fruits of their territory, as well as to offer a contribution to the Northeastern Indians' ethnobotany. An ethnographic methodology was chosen conjointly with a qualitative approach. Indigenous tribes preserve the natural resources and knowledge associated with them while keeping alive their cultural diversity.
\end{abstract}

Keywords: fruits; ethnobotany; traditional knowledge.

Résumé: La recherche a essayé de comprendre les connaissances traditionnelles de la Barra do Mundaú Tremembe sur les fruits indigènes de leur territoire et d'apporter une contribution à l'ethnobotanique du Nord indigène. La méthodologie ethnographique a été élu avec une approche qualitative. Les peuples autochtones, la proportion qui défendent la diversité culturelle, préserve les ressources naturelles et les connaissances qui leur sont associées.

Mots-clés: fruits; ethnobotanique ; aux savoirs traditionnels.

Resumen: La investigación se empeñó en comprender el conocimiento tradicional de la tribu Tremembé de la Barra do Mundaú sobre las frutas nativas de su región y en ofrecer una contribución para la etnobotánica de los indígenas del Noreste del Brasil. Se eligió la metodología etnográfica como un abordaje cualitativo. Los pueblos indígenas a medida que defienden la diversidad cultural, también preservan los recursos naturales y sus conocimientos a ellos asociados.

Palabras claves: frutas; etnobotánica; conocimiento tradicional.

\section{INTRODUÇÃO}

Os Tremembé da Barra do Mundaú são um povo indígena que habita o literal do Oeste do Ceará e costumam lidar com plantas que servem para utilidades diversas. Por isso, elas estão presentes na vida desse povo indígena a todo instante; por exemplo, na alimentação humana e animal, na confeç̧ão de artefatos, nos medicamentos, nas práticas de cura e rituais. A complexa relação dos seres humanos com as plantas ensejou debates clássicos da ciência antropológica, nos quais foram elaborados conceitos e teorias em busca da compreensão de práticas e crenças associadas aos vegetais.

\footnotetext{
${ }^{1}$ Universidade da Integração Internacional da Lusofonia Afro-Brasileira (UNILAB), Redenção, Ceará, Brasil.
} 
Nesse contexto, este trabalho insere-se e produz-se no debate atual do campo da etnobotânica, pois aborda os valores e significados atribuídos por um grupo étnico às frutas de seu território, bem como se relaciona com os estudos das ciências sociais a respeito dos povos indígenas do Nordeste. Muitos trabalhos nessa área direcionam seus esforços para a elaboração de listas de plantas úteis, a partir do saber associado, negligenciando os sentidos que as pessoas atribuem aos seus usos, aspecto priorizado nesta pesquisa. Serão igualmente abordadas questões políticas indissociáveis da discussão étnica relativas ao uso sustentável dos recursos naturais e ao direito ao território, foco das reivindicações do movimento indígena.

Garantir os direitos dos povos e comunidades tradicionais é também assegurar a sustentabilidade, uma vez que as áreas protegidas por terras indígenas ainda constituem espaços de proteção dos recursos naturais, mesmo com todas as ameaças aos seus modos diferenciados de vida. Nesse sentido, é fundamental dar visibilidade à luta indígena pela preservação de seus conhecimentos e pela garantia de seus direitos.

A pesquisa elegeu a metodologia etnográfica, com abordagem qualitativa, cuja intenção foi adentrar no universo dos Tremembé, para que, assim, compreenda seus processos de construção de conhecimento, as particularidades dos grupos, as formas de usos das frutas da sociobiodiversidade e como vivenciam e representam, para si e para os demais, esse saber tradicional. Para Geertz (1989), praticar etnografia é, dentre outras coisas, estabelecer relações, selecionar colaboradores da pesquisa a serem entrevistados, transcrever textos, mapear campos, manter um diário e assim por diante.

Além de buscar uma reflexão antropológica acerca do conhecimento etnobotânico dos Tremembé da Barra do Mundaú sobre as frutas da sociobiodiversidade, este trabalho faz referência a conhecimentos produzidos por outras áreas, especialmente pela botânica. Por um lado, os estudos antropológicos foram fundamentais à compreensão de conceitos como os de etnicidade e conhecimento tradicional; por outro, os estudos biológicos forneceram valiosos subsídios para entender a etnobotânica, perceber a biodiversidade de espécies e ecossistemas presentes na Terra Indígena e a relevância para a cultura daquele povo.

O trabalho busca - no âmbito teórico - embasamento para compreender a questão da identidade étnica dos Tremembé da Barra do Mundaú. Assim sendo, diversos autores já realizaram pesquisas com os Tremembé que habitam na Praia de Almofala, no município de Itarema, reconhecida como seu lugar de origem pelos indígenas da Barra do Mundaú. As narrativas étnicas servem para que os grupos criem ou resgatem sinais diacríticos; a saber, símbolos e performances que irão caracterizá-los e diferenciá-los da sociedade envolvente.

O trabalho também aponta a importância do território para a reprodução física e cultural do grupo étnico, considerando-se as formas de uso diferenciadas dos seus recursos naturais. Nesse sentido, observam-se, no território dos Tremembé, os sinais da presença pretérita de grupos indígenas nos cinco sítios arqueológicos existentes. Esse grupo indígena considera esses locais tais como moradas de encantados e observa neles um vínculo com seus ancestrais, bem como um cenário para a construção de suas narrativas étnicas. Ainda nessa investigação, apresentam-se as bases teóricas para se construir o conceito de etnobotânica. Por isso ressalta-se a necessidade de se valorizar os produtos da sociobiodiversidade como forma de facilitar o desenvolvimento sustentável.

A pesquisa descreve a luta Tremembé da Barra contra a especulação imobiliária, manifestando vitórias que fortaleceram a trajetória de resistência do grupo. Como resultado dessa 
luta, o Ministério Público Federal (MPF) propôs uma ação judicial, cujo objeto foi a demarcação da terra, de modo que teve como órgão interessado na demanda a Fundação Nacional do Índio (Funai). Mostra-se ainda a importância do torém na construção da identidade indígena e a maneira como os Tremembé se autocompreendem a partir dessa manifestação ritual. Ademais, faz um relato etnográfico da VII Festa do murici e do batiputá, descrevendo a rotina de coleta dos frutos, durante a semana da festa. Igualmente, são descritas as atividades culturais organizadas pelos grupos da comunidade, apontando-se a relevância cultural dessas frutas reverenciadas pelos Tremembé.

Portanto o trabalho empenhou-se em compreender o conhecimento tradicional dos Tremembé da Barra do Mundaú sobre as frutas nativas de seu território e em proporcionar uma contribuição para a etnobotânica dos indígenas do Nordeste.

\section{REFERENCIAL TEÓRICO}

\subsection{Identidade étnica}

Uma das primeiras premissas da abordagem antropológica a grupos étnicos indica que esses grupos se constituem como categorias atributivas e identificadoras, empregadas pelos próprios atores. São os indígenas, no caso a ser estudado, que se autodenominam como tais; e assim elaboram ou adotam um conjunto de sinais diacríticos que lhes permite autoafirmarem-se enquanto indígenas. Esses sinais se manifestam no vestuário, no modo de falar, nas moradias, na cultura alimentar etc., e são expressos para os não índios, de forma interna e externa ao grupo; enfim, para a sociedade envolvente. Para Barth (2000), as distinções interétnicas não dependem de isolamento ou ausência de interação com outras culturas; mas sim, da organização e mobilização de suas instâncias representativas em torno da autoidentificação e da concessão de direitos. As interações entre grupos distintos podem reforçar as diferenças, à medida que há o estranhamento do outro e o esforço performático pela autoafirmação.

Esses sinais - assim como a cultura - não são estáticos, porquanto se alteram de modo a melhor cumprir sua finalidade. Apesar dos conflitos e dos contatos interétnicos, os sinais diacríticos permanecem. Nesse sentido, o trabalho etnográfico deve focar sua atenção para aquilo que o grupo reivindica como seu; ou seja, como parte de sua identidade, bem como para o conhecimento e discurso que o grupo emprega para interpretar e dar sentido às suas vidas.

No caso dos Tremembé, esses símbolos podem ser percebidos em seu conhecimento e relação com os recursos naturais, bem como em suas práticas religiosas específicas. Em vista disso, os símbolos, embora se confunda com a Umbanda, visto que possui elementos desta, constituem-se como uma religiosidade própria, a qual é trabalhada com a reunião de vários elementos.

A demarcação de terras indígenas no Brasil é o reconhecimento por parte do Estado brasileiro do direito histórico das populações indígenas ao uso e usufruto de seus territórios. Dessa maneira, há uma distinção mais clara entre as populações indígenas e as não indígenas, fundada no conceito de etnia e no reconhecimento de uma continuidade sociocultural, histórica e identitária das sociedades e culturas indígenas.

Gonçalves (1994, p. 87) conclui que não se devem privilegiar somente dados históricos, quando se trata de definir terras de ocupação tradicional indígena, porque o tradicionalmente do texto constitucional ( $\S 1$ 으. art. 231, CF/88) não se refere a tempo pretérito; senão, à forma 
de ocupação de um dado território no presente. Isso implica dizer também da ocupação atual, segundo culturas e tradições, as quais são bastante dinâmicas.

Quando se observa um grupo enquanto portador de uma cultura distinta, suas diferenças tendem a se destacar, de forma a serem percebidas pelas distinções de um inventário de traços culturais. O exótico e o diferente são exaltados em detrimento de sua organização étnica, pois negligencia-se sua etno-história, o que explica as causas dos empréstimos de certos itens e esforços de autoafirmação étnica. Esses empréstimos se deram por meio de diferentes formas de contato, de maneira que foram incorporados à cultura de ambos os grupos em contato. Isto nos chama a atenção para não relacionar a ideia de cultura à de isolamento demográfico.

Oliveira (1999, p. 16-17) assegura que os povos indígenas do Nordeste foram expostos ao órgão indigenista como objetos de atenção para a Antropologia a partir de demandas, relativas à terra e à assistência. Segundo o citado, a partir do desenvolvimento de diversos estudos, foi possível elaborar um primeiro esforço de definição da categoria de índios do Nordeste como uma unidade étnica e histórica integrada, nas palavras de Dantas, Sampaio e Carvalho (1992 apud OLIVEIRA, 1999, p. 16), pelos "diversos povos adaptativamente relacionados à caatinga e historicamente associados às frentes pastoris e ao padrão missionário dos séculos XVII e XVIII".

O conceito de índios do Nordeste elaborado por Oliveira (1999) relaciona-se com as instituições indígenas, sua história e seu território, sendo determinado por seu pertencimento ao Nordeste, na condição de conglomerado histórico e geográfico. Amiúde, vistos pela sociedade envolvente como índios misturados, agrega-Ihes uma série de atributos negativos que os desqualificam e os opõem aos índios puros. Logo, a mistura é oriunda de um processo histórico de violência que mudou o modo de ser desses povos que precisaram se reinventar. Por fim, não cabe investigação acerca da veracidade da autoidentificação de um povo, na medida em que se reconhece que as culturas são realidades em movimento e os povos têm direito à sua autodeterminação.

Souza Lima (2002) ressalta que, em uma perícia antropológica, o relatório de identificação e delimitação da Funai serve para confirmar ou negar que a área em questão é de ocupação de um grupo indígena, considerando-se que o grupo já se autoidentifica. A demarcação das terras se constitui como uma política compensatória, de sorte que pretende minimizar as violências do colonialismo praticadas a essas populações.

\subsection{Etnoconhecimento e território}

O conhecimento tradicional, também denominado etnoconhecimento ou saber local, diz respeito a conjuntos de conhecimentos construídos e reconstruídos no seio de dada população tradicional. Ele é um ponto presente na discussão acerca da reprodução cultural de grupos étnicos. Esse conhecimento que constitui o patrimônio imaterial de um povo, distingue os grupos e faz parte de sua identidade cultural. Em decorrência disso, a relação íntima dele com o território e com os recursos naturais disponíveis acabam produzindo as bases para a construção de um conhecimento intimamente ligado à identidade desses grupos que, para a sua sobrevivência e constituição identitária, dependem de suas terras.

Um elemento importante na interação das populações tradicionais com os recursos naturais é a relação com seu território, definindo-se como uma porção da natureza e espaço sobre o qual uma sociedade determinada garante a seus membros, através de reivindicações políticas, 
direitos estáveis de acesso, controle ou uso sobre os recursos naturais aí existentes necessários à sua sobrevivência (GODELIER, 1984 apud DIEGUES, 1999, p. 19). Nesse sentido, Santilli (2005, p. 94) também compartilha dessa mesma ideia ao compreender o território como "o espaço necessário à reprodução física e cultural de cada grupo, considerando suas formas de uso diferenciadas". Tal conceito, não guarda relação com o tempo imemorial; mas sim, com os usos e costumes dos povos e comunidades tradicionais, traduzindo uma ocupação coletiva do espaço, onde predominam o uso e a gestão compartilhada dos recursos naturais.

Os Tremembé demonstram sofisticado conhecimento ecológico, transmitido de geração a geração. São conhecimentos etnobotânicos e etnobiológicos desenvolvidos a partir da cosmologia Tremembé, bem como da convivência dos antigos com o meio ambiente, com a terra e com suas formas de vida. Os Tremembé conhecem profundamente bio-indicadores, etologia de algumas espécies e sua relação com a alternância das fases do ciclo hidrológico e com a biogeografia dos corpos d'água do seu território. A agricultura e o extrativismo são as principais fontes alimentares de origem vegetal e de carboidratos para os Tremembé. Por sua vez, eles apresentam um sistema detalhado de classificação de ambientes terrestres e aquáticos, o que demonstra o conhecimento acumulado ao longo da ocupação duradoura e tradicional na área que posteriormente foi delimitada. No campo da cosmologia, cabe destacar que o torém é o principal ritual sagrado praticado pelos Tremembé (FRANCO, 2012).

Preservar as encantarias e o vínculo com os ancestrais, além de serem experiências de busca pelo sagrado, é expresso pelos Tremembé como uma condição para a preservação dos recursos naturais. Esse liame com os ancestrais se expressa no conhecimento do território, que faz com que esses grupos reverenciem recursos naturais, relacionando sua energia com a força de seus antepassados e dando significado à sua identidade étnica, em uma simbiose com seu território. Os ritos de manifestação dos encantados, como um sinal diacrítico interno ao grupo englobam, de modo existencial, realidades múltiplas; tais como, religiosidades indígenas, manifestações do catolicismo popular e afro-brasileiras, práticas terapêuticas e formas de organização étnica capazes de fortalecer o grupo, tanto para suas necessidades pessoais de curas quanto para os embates nas lutas por seus direitos (BRISSAC; NÓBREGA, 2010).

Em uma pesquisa etnográfica é relevante, a partir dos usos e dos saberes, observar as representações, mitos e crenças acerca de seu território e de seus recursos naturais, os tabus alimentares, a ciência do fazer, do curandeiro que sabe a hora e a lua ideais para se colher determinada fruta que servirá para o preparo do remédio ou da bebida ritualística.

A construção da ideia de região em Bourdieu (2001) está diretamente relacionada à noção de etnia que, por sua vez, se relaciona com a noção de identidade e unidade do grupo. A cultura que une um grupo em torno de sua identidade é a mesma que o separa e o faz distinto de outros grupos. Nesse sentido, o território, lugar de origem, cuja etimologia conduz ao princípio da divisão, possui um papel fundamental nessa construção, pois se constitui no cenário em que as representações mentais criarão a ideia de si mesmas, para dentro e para fora do grupo. As lutas em torno da identidade étnica ou regional estão ligadas à origem, por meio do lugar de formação do grupo e dos sinais que os distinguem enquanto tal. Para o autor, o que está em jogo é o poder de impor sua visão do mundo social sobre a identidade e a unidade do grupo.

No contexto sociopolítico em que essas populações estão inseridas, essa caracterização é a que tem, muitas vezes, legitimado uma identidade diferenciada e fundamentada no plano das relações com o Estado, que é a reivindicação por direitos territoriais e culturais específicos 
(DIEGUES, 1999). Os Tremembé não somente reivindicam sua terra como base para a construção de sua identidade, mas também buscam políticas públicas específicas.

Quando os dominados, ou um grupo vulnerável como os Tremembé, entram em uma relação de forças simbólicas, em estado isolado, não têm outra escolha, a não ser a da aceitação da definição dominante de sua identidade ou a busca da assimilação, o que pressupõe um trabalho que faça desaparecer todos os sinais destinados a lembrar do estigma - estilo de vida, vestuário, fala etc. (BOURDIEU, 2001). Os Tremembé, partindo de um longo processo de opressão e dispersão, vêm resgatando a identidade expropriada junto com sua terra e com o processo de aculturação. Isso tem como ponto central a integração do índio à chamada civilização brasileira e a negação de sua identidade, enquanto raça, por parte da sociedade envolvente.

\subsection{Conhecimento etnobotânico}

Desde a antiguidade, grupos se preocupam em resgatar o conhecimento referente ao uso que outros povos fazem dos elementos de seu ambiente natural. Nesse contexto, se inserem os saberes referentes ao mundo vegetal. Com base nos estudos realizados, a etnobotânica é definida como sendo o estudo das inter-relações materiais e simbólicas entre o ser humano e as plantas, somando-se os fatores ambientais e culturais, bem como os conceitos locais que são desenvolvidos acerca das plantas e os usos que se fazem delas (JORGE, 2003 ).

O conceito de etnobotânica foi desenvolvido ao longo de muitos anos e foi sendo ampliado a partir da integração de áreas como botânica, antropologia, ecologia, química, engenharia florestal e agronomia. Logo, de acordo com Prance (1997), a participação de pesquisadores dessas áreas possibilita novos progressos nas pesquisas etnobotânicas, abordando de forma multidisciplinar a forma como as pessoas percebem, classificam e utilizam as plantas. Para o autor, é a partir dos trabalhos de Carl Linnaeus que se inicia a história da etnobotânica, pois seus diários de campo tinham anotações acerca das culturas visitadas e seus hábitos relativos ao uso das plantas.

O trabalho de Oliveira et al. (2009) acerca das pesquisas etnobotânicas realizadas entre os anos de 1968 a 2007 mostra que, dentre o vasto universo de estudos relacionados à temática, predominam as pesquisas referentes às plantas medicinais e/ou abordagens descritivas. O caráter interdisciplinar e integrador da etnobotânica alia fatores culturais e ambientais e, por ser uma disciplina relativamente nova, sob os domínios da botânica e da etnografia botânica, não tem sido sistematizada e formalizada como outras ciências já estabelecidas.

No Brasil, essa nova ciência acompanha o surgimento e o fortalecimento do movimento dos povos indígenas, dos seringueiros e dos quilombolas, com propostas concretas de áreas protegidas como as reservas extrativistas (DIEGUES, 1999, p. 11), porquanto a maioria das pesquisas realizadas foram desenvolvidas na América Latina, por pesquisadores estrangeiros, e os trabalhos iniciais tinham um caráter descritivo, com objetivo de catalogar plantas 'úteis' de uma região, no sentido de reunir informações sobre novos produtos.

A junção da biologia com a antropologia qualificou os estudos etnobotânicos com o reconhecimento da pesquisa de campo. Contudo a falta de comunicação entre as disciplinas mostrou falta de treinamento por parte dos botânicos para a coleta de dados no tocante ao conhecimento das plantas. Já por parte dos antropólogos, faltavam-Ihes informações sobre as espécies vegetais utilizadas (OLIVEIRA et al., 2009). 
Em se tratando de metodologia, Posey (2001) considera que uma das principais barreiras a serem transpostas nas pesquisas interdisciplinares são as diferentes formas de relacionar métodos entre os cientistas sociais e naturais, uma vez que ambos possuem formas diferentes de trabalho de campo e coleta de dados. Os biólogos podem considerar a necessidade de menos tempo em campo para coletar amostras e classificar; já os antropólogos, por sua vez, podem necessitar de um período maior para uma observação participante capaz de sondar percepções e conceitos nativos.

O texto do antropólogo Posey (1987) é de uma grande sensibilidade etnográfica. Seus trabalhos abordam o conhecimento indígena, conceitos cognitivos e categorias folk, padrões de classificação e nomenclatura. O autor afirma sentir a etnobiologia como uma filosofia, e não apenas como uma metodologia, demonstrando opinião contrária à versão utilitarista dos recursos naturais. O texto reflete sobre formas de classificação a partir de seu trabalho com os Kayapó, na Amazônia; além disso, ilustra com desenhos como os Kayapó classificam os recursos florestais, seus usos, sua forma de manejo e seus sofisticados conhecimentos etnobotânicos. O autor enfatiza que a etnobiologia pode estabelecer uma ponte de ligação entre diferentes culturas, desde a compreensão de seus modos de ser e pensar, sendo capaz de prover os dados necessários a uma poderosa argumentação em favor das comunidades tradicionais, suas terras e a biodiversidade.

López Garcés e Robert (2012) ressaltam a importância mundial do trabalho de Posey para a proteção do conhecimento tradicional dos povos indígenas e de seus territórios, destacando sua contribuição para a normatização jurídica brasileira relativa a pesquisas em etnobiologia no Brasil. Posey acreditava que a etnobiologia poderia ser uma alternativa para o desenvolvimento dos povos indígenas e comunidades tradicionais, cujos conhecimentos ecológicos, desenvolvidos durante milênios, poderiam vir a ser aplicados na geração de novas tecnologias sustentáveis.

\section{RESULTADOS E DISCUSSÃO}

\subsection{Os Tremembé da Barra do Mundaú}

A Funai, mediante o processo FUNAI/BSB n. 08620.003184/2012-16, aprovou, em 2012, o Relatório Circunstanciado de Identificação e Delimitação de autoria do Grupo Técnico coordenado pela antropóloga Cláudia Tereza Signori Franco, que identifica a Terra Indígena Tremembé da Barra do Mundaú, como de ocupação tradicional do grupo indígena Tremembé, com área de 3.580 hectares, localizada no município de Itapipoca, Estado do Ceará.

Existem na área duas comunidades que, antes do estudo antropológico, definiam o grupo como os Tremembé de São José e Buriti, para diferenciá-los dos Tremembé de Almofala. Com a delimitação, ficou acordado com a comunidade que a terra passaria a ser chamada de Tremembé da Barra do Mundaú, como referência à sua localização geográfica junto à foz do referido rio.

No ano de 2002 apareceu, na região a Nova Atlântida, grupo empresarial espanhol com o projeto de erguer na área ocupada pelos Tremembé um complexo turístico e residencial composto por 27 hotéis e resorts, seis condomínios residenciais e três campos de golfe. Diante dessa ameaça a seus direitos, os Tremembé apresentaram, em 2004, representação ao Ministério Público Federal (MPF), que abriu procedimento sobre a questão.

A partir do estudo realizado pelo geógrafo Jeovah Meireles e pela arqueóloga Marcélia Marques, o MPF ingressou, em 2005, com ação civil pública contra a empresa e a Superintendência 
Estadual do Meio Ambiente (SEMACE), buscando impedir a implantação do complexo hoteleiro e anular licenciamento do empreendimento. Na medida em que a área em litígio é terra tradicionalmente ocupada pelos índios, de acordo com a Constituição Federal, eles têm direito ao seu uso e usufruto exclusivo. Foi concedida pela Justiça Federal uma liminar favorável aos indígenas; por conseguinte, desde 2005 , foi impedida a implantação do projeto, posto que tenham sido apresentados pela empresa vários recursos às instâncias superiores. Não obstante, tais recursos foram ocasiões de reiteradas decisões favoráveis aos indígenas. Em 2007, a imprensa denunciou indícios de lavagem de dinheiro nas atividades da Nova Atlântida.

Mesmo após a propositura da ação pelo MPF, o grupo empresarial continuava atuando na área, buscando segmentar a comunidade e cooptar os moradores não indígenas, contratando pessoas para serviços pontuais e difundindo a ideia de que a implantação do empreendimento traria excelentes condições de vida e emprego para a população local. Apesar de toda a pressão, a comunidade continuou se organizando e exigindo a atuação dos órgãos governamentais. Ainda em 2005, MPF expediu recomendação à Funai para que nomeasse Grupo Técnico (GT) para a identificação e delimitação da Terra Indígena e a reiterou em 2007. Em 2009, a Funai nomeou o GT que no mesmo ano realizou o seu trabalho de campo.

Em 2012 foi publicado no Diário Oficial da União o resumo do relatório de identificação e delimitação. E, finalmente, em 7 de agosto de 2015, foi assinada e publicada pelo ministro da Justiça uma Portaria declarando a Terra Indígena Tremembé da Barra do Mundaú (BRASIL, 2015). A referida Portaria traduz-se como um ato por meio do qual o Estado brasileiro reconhece que determinada porção do território nacional é de ocupação tradicional de um povo indígena, cabendo-lhe o seu uso e usufruto exclusivo. Ainda deve ser efetuada a desintrusão dos não indígenas e a posterior homologação da Terra Indígena, através de decreto do presidente da República. Após mais de 11 anos de tramitação da ação civil pública na Justiça Federal, em 12 de julho de 2016, foi proferida a sentença, condenando a empresa a se abster de qualquer intervenção no imóvel, em face do interesse federal decorrente da presença da comunidade indígena Tremembé e declarando a nulidade do procedimento de licenciamento levado a efeito pela SEMACE.

As primeiras referências aos Tremembé datam do século XVI. Os jesuítas começaram a estabelecer aldeamentos em território cearense no século XVII, paralelamente ao processo de concessão de sesmarias na zona costeira. O projeto colonial português promovia uma política que categorizava os povos indígenas em dois polos, os aliados e os inimigos, o que resultava em justificativas para o emprego da força física. Desde então, a luta de resistência dos indígenas cearenses tem sido incansável, tendo em vista que os povos considerados aliados eram catequisados e convertidos ao cristianismo, já os índios bravos, eram submetidos à força militar e política (FRANCO, 2012).

Os Tremembé, cuja presença foi documentada na área de litoral desde o Maranhão até o Ceará, habitam hoje áreas no litoral e no interior do Ceará, especificamente nos municípios de Itarema, Acaraú e Itapipoca. Atualmente, a população total é de aproximadamente 3 mil pessoas. Conforme Franco (2012), dados de 2009 apontam que viviam na Terra Indígena Tremembé da Barra do Mundaú 494 indígenas. Entretanto, os Tremembé relatam que sua terra de origem é Almofala; de lá, os grupos teriam migrado para outros municípios e se dispersado. Franco (2012) aponta que vários pesquisadores propõem que os Tremembé seriam descendentes dos Tapuia/ Cariri e que deveriam ter falado originalmente uma língua diversa daquelas pertencentes ao tronco Tupi. 
Os Tremembé falam o português, vestem-se indistintamente e têm hábitos semelhantes às comunidades não indígenas adjacentes às suas terras. Da mandioca, fabricam a farinha de puba (farinha grossa) e o beiju e com o caju, o mocororó, bebida ritualística e medicinal, ingerida nos dias em que se dança o Torém. Várias frutas são coletadas, de acordo com a necessidade e a sazonalidade. Da fruta, chamada batiputá, eles extraem um óleo de uso alimentar e fazem variadas aplicações medicinais. Na época da colheita, que coincide com a do murici, é celebrada a festa do murici e do batiputá.

Comparando os dois grupos Tremembé, os de Almofala e os de Itapipoca, percebe-se distintas formas de manifestação cultural, observadas principalmente no torém e no artesanato. Barth (2000), que recomenda a comparação entre grupos da mesma sociedade; porém, de localidades diferentes, explica a existência de variáveis de uma mesma cultura a partir das diferentes condições ecológicas em que os subgrupos vivem.

Um estudo complementar pode identificar com mais propriedade essas diferenças que não foram foco desse trabalho; no entanto podemos destacar, a partir do artesanato dos Tremembé de Almofala, a presença de um tipo de concha que só existe naquela região e que constitui a matéria-prima mais característica do artesanato tremembé de Almofala. Constatou-se, pois, que os símbolos se modificam, face aos interesses e às necessidades dos diferentes grupos, incorporam e descartam elementos, ganhando novas formas de representação.

De acordo com Oliveira (1999, p. 22), parte das populações indígenas que hoje habitam o Nordeste, emana das culturas autóctones envolvidas em processos de territorialização na segunda metade do século XVII e nas primeiras décadas do século XVIII, associados às missões religiosas, ressaltando-se que essas famílias, de diferentes línguas e culturas, foram sedentarizadas e catequizadas. Segundo o autor, desse contingente procede parte das denominações indígenas do Nordeste.

Oliveira (1999) destaca que, dentre os componentes principais dessa indianidade, estava a estrutura política, cacique, pajé e conselho indígena e os rituais diferenciadores como o toré e o torém. Quanto à estruturação política, os Tremembé da Barra do Mundaú preferiram não distinguir lideranças como cacique e pajé, embora haja pessoas que assumam essas funções. Essa medida descentraliza o poder, fazendo com que as lideranças se revezem nas representações em eventos fora da aldeia. O torém é uma dança circular, semelhante ao toré, realizada pelos Tremembé, como um sinal de expressão de sua indianidade. As letras das músicas utilizadas pelos Tremembé da Barra do Mundaú fazem referência à sua espiritualidade, à identidade étnica e à sua realidade política. É realizada com reverência, de forma ritualística. O torém, assim como o toré, dançado por outros povos indígenas do Nordeste, ganhou visibilidade como uma brincadeira de índio, com valor folclórico, que foi se politizando e ganhando importância política, ritualística e de mobilização étnica (OLIVEIRA JR, 1998; VALLE, 1992 GRÜNEWALD, 2005).

Frente às ameaças à sua organização política, o grupo busca elaborar um discurso de exaltação da sua identidade étnica Tremembé, cantando para eles e para os não índios, afirmando sua força e comunicando que, acima deles, só Deus pode mais. A terra é o lugar onde se consegue o sustento do corpo e se estabelece a conexão com as forças sobrenaturais que alimentam a alma. Os cânticos fortalecem a narrativa de que a terra é legitimamente indígena, de sorte que, para defendê-la, há um grupo de índios verdadeiros, guerreiros fiéis, prontos para a luta.

Conquanto os Tremembé, por meio do torém, se identifiquem com uma cultura religiosa relacionada com a jurema, eles não fazem uso de bebida à base da planta. Entretanto fazer 
referência à jurema em seu torém é uma forma de comunicação interétnica acerca de suas matrizes culturais e religiosas que, segundo Nascimento (1994), também comunica a forma de organização política de seus agentes. Consoante o autor, o universo da jurema está relacionado com manifestações religiosas sincréticas que, por si só, caracterizam uma indianidade por ser o principal elemento de culto dos torés indígenas, estando presente:

Entre grupos indígenas, nos Torés, Praiás e Ouricuris, como nos rituais afrobrasileiros, os Jarês, Pigis, Candomblés de Caboclo e Xangôs; ou nos não tão afro assim, as Umbandas, os Catimbós, e os sugestivos torés misturados que existem em Sergipe e Alagoas. Em todos eles a jurema está sempre referida a alguma representação do índio. Ademais, podem ser encontradas referências bem antigas a seu respeito. (NASCIMENTO, 1994 , p. 65)

Em vista disso, relacionar-se com esse universo é estabelecer uma identidade indígena a partir de seus cultos, construindo para si e para os outros uma imagem étnica que também pode ser observada no seu modo de ser e de viver, de pessoas que adquiram da mata seu sustento, comendo caça, vestindo-se do que a natureza lhes oferece, como no torém da jurema e no torém do murici; logo abaixo:

Minha comida é samambaia, minha roupa é de pena (bis)

Eu vem da jurema, eu vem da jurema, eu vem da jurema, eu vem da ju-juremá.

A sombra do murici é minha rede. A folha é meu lençol.

As flores chamam o vento pra formar nosso alimento.

Ai eu sou índio, eu sou índio Tremembé e eu sou, eu sou índio, sou de fé.

Tremembé na mata apanha murici, apanha murici, apanha murici. (bis).

(Autoria: Tremembé da Barra do Mundaú).

As cantigas de torém revelam ainda uma íntima ligação desse povo com sua terra e uma dependência de seus recursos. O território é a fonte do alimento, da roupa, do leito e do abrigo e sua indianidade é manifestada na relação com esse território e seus recursos, na cata do murici, no culto à jurema e às plantas sagradas. A cultura material e a imaterial dos Tremembé, relacionada ao território, os fazem resgatar uma memória social constituída pelas suas relações cotidianas, econômicas, seus rituais, fazendo emergir aspectos identitários relativos à sua etnicidade.

\subsection{Etnografia da VII Festa do Murici e do Batiputá}

A festa do murici e do batiputá é realizada no mês de janeiro, época da colheita das duas frutas. Essas frutas são tão importantes para os Tremembé que ganham uma comemoração por ocasião de sua safra. A inserção desse ritual no calendário da etnia, baseado em um fenômeno natural, orienta o cotidiano da comunidade durante todo o período de colheita. No ponto alto na semana da festa, que é no sábado, a comunidade desenvolve várias atividades de cunho político, cultural e religioso, que envolvem apresentações teatrais, danças folclóricas, torém, disputas esportivas de modalidades indígenas, preparo e distribuição de refeições coletivas e venda de artesanatos. No ano de 2016, a festa foi realizada entre os dias 12 e 16 de janeiro, de terça-feira a sábado.

A festa é um momento de celebração, ocasião em que as mulheres catam o murici e os homens, o batiputá. Todavia a comemoração é importante para cultivar a cultura de seus antepassados, sendo o murici uma fonte de renda, e o batiputá, fonte de remédio e alimento, que devem ser valorizados. Nas falas das lideranças, nas cantigas e nas orações, estava muito presente 
a exaltação do ser Tremembé e da luta pela terra. A força dos encantados era invocada, de maneira a alimentar a coragem e o espírito guerreiro dos Tremembé, contra os quais ninguém pode mais, pois é Deus no céu e os índios na terra, como diz a letra de uma cantiga de torém. No centro do espaço, uma vasilha com ervas imersas em água para fazer uma limpeza espiritual e abençoar os presentes. Com os galhos das plantas, uma pessoa foi aspergindo todos com a água de ervas no sentido anti-horário do círculo, enquanto falava em voz baixa palavras de poder. Havia ainda uma garrafa com mocororó e uma telha de barro com brasas e incenso. Para encerrar, o grupo rezou a oração dos Tremembé.

O trabalho espiritual dos Tremembé, que evoca a energia dos encantados, baseado em uma narrativa de guerreiros corajosos e persistentes, fortalece a luta pela terra, a sua mobilização étnica e a constância frente às investidas do empreendimento Nova Atlântida e aos demais obstáculos que ameaçam a causa indígena.

As plantas são usadas nos rituais nas formas de banhos ritualísticos, defumação, bênçãos e rezas de cura contra mal olhado, quebranto e limpeza espiritual. Dentre as plantas utilizadas nos trabalhos espirituais, foram citadas algumas, com seus respectivos usos, cujas folhas utilizadas são: juá (banho), guabiraba (banho), limão (incenso), ameixa (incenso), ata (banho), manga (banho), caju (banho), graviola (banhos). Uma das formas citadas para a realização de banho é a seguinte: utilizam-se nove folhas (que devem ser lavadas); em seguida, maceram-se em dois litros d'água; depois, coam-se; e, por fim, após a higiene corporal normal, a pessoa (que está sendo submetida ao tratamento), deve banhar-se (com líquido resultante da prescrição). Ressalta-se também que cada folha tem uma força diferente, tem que ser a folha nova, do olho da planta, pois elas estão em crescimento, em ascensão.

O local da colheita era uma das matas de murici existentes na comunidade, bem afastada e isolada das áreas de moradia. Era numa mata baixa, cuja vegetação tinha em média 3 metros de altura, formada com grande concentração de pés de murici, conhecida por pessoas da comunidade por sua boa produtividade. No salão do ponto de apoio, ficava localizado um grande recipiente plástico em que as pessoas depositavam as frutas colhidas individualmente.

Para o processo de limpeza e seleção das frutas, as mulheres sentavam no chão e separavam os frutos do murici de seu pedúnculo (que é o talo que liga a fruta à planta). Um recipiente grande continha as frutas inteiras que eram separadas de seu pedúnculo e colocadas em um recipiente menor. Impurezas como folhas, galhos, areia ou insetos, também eram retiradas, deixando somente frutas sem talos, de modo que depois eram lavadas, colocando-se água no recipiente e retirando-a em seguida. Toda essa atividade consistia em um momento de socialização do grupo, com muita conversa e descontração.

No segundo dia, um grupo formado por homens, adultos e crianças, assumiu a colheita do batiputá. Cada pessoa usava dois recipientes para colher o batiputá, um pequeno, utilizado na retirada das frutas dos galhos, aparando-as em seguida à sua extração e um balde, no qual as pequenas quantidades eram colocadas. A colheita era feita com movimentos semelhantes à do café, pois se fechava o punho delicadamente ao redor dos cachos e puxavam-se as frutas cuidadosa e rapidamente para baixo, fazendo com que elas se soltassem e caíssem no pequeno recipiente que, ao se encher, alimentava o balde.

Entre os Tremembé, o aprendizado quanto ao trato com as frutas se dá no âmbito familiare nos momentos de socialização do grupo, como na festa do murici e do batiputá. Lá, as atividades são realizadas em espaços abertos, na presença de todos e com participação coletiva. 
A relação intergeracional permite que o conhecimento seja repassado com naturalidade. 0 jovem observa a pessoa experiente que faz o óleo de batiputá; ao mesmo tempo, participa dos processos iniciais para que sua produção seja possível, como a colheita e a seleção, para mais tarde ser iniciado na arte, propriamente dita, de fazer o óleo, com a vivência e o conhecimento de todas as etapas anteriores ao preparo. Quando os indivíduos demonstram assumir lugares de destaque na organização política, os jovens já podem vislumbrar assumir esses papéis. Em virtude disso, são formadas novas lideranças, que assumirão a luta em defesa da terra e da sua identidade étnica.

\section{CONSIDERAÇÕES FINAIS}

A relevância das frutas para os Tremembé vai além do aspecto nutricional, vinculando-se ao conhecimento tradicional que o povo indígena sabe sobre esse recurso, relacionado com suas práticas culturais nas diversas modalidades. Tais práticas culturais são consideradas elementos de distinção com outros grupos sociais; o que, portanto, faz-se com que sua identidade indígena torne-se mais fortalecida.

As matas de murici e de batiputá, consideradas frutas sagradas para esse povo, são um exemplo do elo que se estabelece entre o povo e a sua terra tradicionalmente ocupada. O fato de os Tremembé conhecerem e utilizarem frutas de suas matas, ignoradas pela maioria das pessoas não-indígenas, demonstra sua íntima relação com o território e seus recursos naturais.

O conhecimento tradicional sobre as frutas nativas, reverenciadas pelos Tremembé em suas cantigas de torém, é um ponto que pode ser aprofundado em pesquisas futuras. Percebese, por exemplo, que seu uso alimentar, medicinal, ritualístico e seu potencial econômico para essas comunidades podem se caracterizar como formas de resistência frente às investidas da especulação imobiliária, à erosão genética e à degradação dos recursos naturais. Dessa maneira, ocorre não apenas uma contribuição muito valorosa para cultura Tremembé, mas ainda uma melhoria da condição nutricional da comunidade indígena.

O eixo central das reivindicações do movimento indígena é o território. Com ele, entrelaçam-se as manifestações culturais do povo que o habita. Indissociável da discussão antropológica sobre etnicidade, tal eixo é a base física de reprodução do grupo, o lugar de pesca, lavoura e farinhada, o cenário de produção das narrativas e da criação dos marcos referenciais da etnia.

Em virtude do exposto, ao lutarem pelo direito ao seu território tradicional, os povos indígenas, à proporção que defendem a diversidade cultural, preservam os recursos naturais e os conhecimentos a eles associados; dando-se, portanto, continuidade à resistência de seus ancestrais e projetando um futuro sustentável para o planeta.

\section{AGRADECIMENTOS}

À CAPES pelo apoio financeiro. 


\section{REFERÊNCIAS}

BARTH, Fredrik. Os grupos étnicos e suas fronteiras. In: LASK, Tomke. O guru, o iniciador e outras variações antropológicas. Rio de Janeiro: Contra Capa Livraria, 2000. p. 25-68.

BRASIL. Constituição da República Federativa do Brasil. Brasília: Senado Federal, 1988.

Portaria n. 1318, de 7 de agosto de 2015. Define os limites da Terra Indígena Tremembé da Barra do Mundaú. Diário Oficial da União, p. 33, Brasília, DF, 11 ago. 2015. Disponível em: <http://pesquisa. in.gov.br/imprensa/jsp/visualiza/index.jsp?jornal=1\&pagina=33\&data=11/08/2015>.

BRISSAC, Sérgio Góes Telles; NÓBREGA, Luciana Nogueira. Benzedeiras Anacé: a relevância dos ritos de cura na emergência étnica de um povo indígena do Ceará. REUNIÃO BRASILEIRA DE ANTROPOLOGIA, 27., 1-4 ago. 2010, Belém, Pará. Anais... Belém: ABA/UFPA, 2010. Disponível em: <xa.yimg.com/kq/ groups/21653234/2036643194/name/Benzedeiras +Anacé.pdf>. Acesso em: 18 jun. 2016.

BOURDIEU, Pierre. O poder simbólico. 4. ed. Rio de Janeiro: Bertrand Brasil, 2001.

DIEGUES, Antonio Carlos. (Org.). Os saberes tradicionais e a Biodiversidade no Brasil. São Paulo: Ministério do Meio Ambiente/COBIO/NUPAB, 1999.

FRANCO, Cláudia Tereza Signori. Resumo do Relatório Circunstanciado de Identificação e Delimitação da Terra Indígena Tremembé da Barra do Mundaú. Diário Oficial da União, n. 26, seção 1, segunda-feira, 6 fev. 2012. p. 22-23.

GEERTZ, Clifford. A interpretação das culturas. São Paulo: LCT, 1989.

GONÇALVES, Wagner. Terras de ocupação tradicional: aspectos práticos da perícia antropológica. In: SILVA, O. S.; LUZ, L.; VIEIRA, C. M. (Org.). A perícia antropológica em processos judiciais. Florianópolis: UFSC, 1994. p. 75-83.

GRÜNEWALD, Rodrigo de Azeredo (Org.). Toré: regime encantado do índio do Nordeste. Recife: Fundaj, 2005.

JORGE, S.S.A.; MORAIS, R.G. Etnobotânica de Plantas Medicinais. In: COELHO, M.F.B; JÚNIOR, P.C.; DOMBRESKI, J.L.D. (Org.). Diversos olhares em etnobiologia, etnoecologia e plantas medicinais. Cuiabá. MT, p.89-98, 2003

LÓPEZ GARCÉS, Cláudia Leonor; ROBERT, Pascale. El legado de Darrell Posey: de las investigaciones etnobiológicas entre los Kayapó a la protección de los conocimientos indígenas. Boletim do Museu Paraense Emílio Goeldi. Ciências Humanas, v. 7, n. 2, p. 565-80, maio/ago. 2012.

NASCIMENTO, Marco Tromboni de Souza. O Tronco da Jurema - ritual e etnicidade entre os povos indígenas do Nordeste: o caso Kiriri. 1994. 324 f. Dissertação (Mestrado em Sociologia)- Universidade Federal da Bahia, Salvador, BA, 1994.

OLIVEIRA JR., Gerson Augusto de. Torém: brincadeira dos índios velhos. São Paulo: Annablume; Fortaleza: Secretaria da Cultura e Desportos, 1998.

OLIVEIRA, Flávia Camargo et al. Avanços nas pesquisas etnobotânicas no Brasil. Acta Botanica Brasilica, Belo Horizonte, v. 23, p. 590-605, 2009.

OLIVEIRA, João Pacheco de. Uma etnologia dos "índios misturados"? Situação colonial, territorialização e fluxos culturais. In: (Org.). A viagem da volta: etnicidade, política e reelaboração cultural no Nordeste indígena. Rio de Janeiro: Contra Capa, 1999. p. 11-39.

POSEY, Darrell Addison. Interpretando e utilizando a "realidade" dos conceitos indigenas: o que é preciso aprender dos nativos? In: "Espaços e Recursos Naturais de Uso Comum". A.C. Diegues e A.C. Moreira (organizadores). NUPAUB, São Paulo, 2001.

Etnobiologia: teoria e prática. In: RIBEIRO, Berta Gleizer (Coord.). Suma etnológica brasileira. Petrópolis: Vozes, 1987. p. 15-25.

PRANCE, Ghillean Tolmie. Etnobotânica de algumas tribos da Amazônia. In: RIBEIRO, Berta Gleizer (Coord.). 
Suma etnológica brasileira. Edição atualizada - Handbook of south american indians. Petrópolis, RJ: Vozes, 1997. p. 119-33. v. 1.

SANTILLI, Juliana. Socioambientalismo e novos direitos: proteção jurídica à diversidade biológica e cultural. São Paulo: Petrópolis, 2005.

SOUZA LIMA, Antônio Carlos de. Os relatórios antropológicos de identificação de terras indígenas da Fundação Nacional do Índio: notas para o estudo da relação entre antropologia e indigenismo no Brasil, 1968-1985. In: SOUZA LIMA, Antônio Carlos de; BARRETTO FILHO, Hênyo Trindade. Antropologia e identificação: os antropólogos e a identificação de terras indígenas no Brasil, 1977-2002. Rio de Janeiro: Contra Capa, 2002. p. 75-118.

VALLE, Carlos Guilherme Octaviano do. Os Tremembé, grupo étnico indígena do Ceará (laudo antropológico). Rio de Janeiro: PETI/Museu Nacional, 1992.

\section{Sobre os autores:}

André Luís Aires Pinto: Mestre em Sociobiodiversidade e Tecnologias Sustentáveis (MASTS/ UNILAB) . Bolsista da CAPES. E-mail: andre.nutre@gmail.com

Maria Jardenes de Matos: Aluna do MASTS/UNILAB. Bolsista da Funcap. E-mail: jardenesmatos@hotmail.com

Maria do Socorro Moura Rufino: Professora da Universidade da Integração Internacional da Lusofonia Afro-Brasileira (UNILAB). Mestrado Acadêmico em Sociobiodiversidade e Tecnologias Sustentáveis (MASTS). E-mail: marisrufino@unilab.edu.br 